\title{
PINEAL GLAND: ITS RÔLE IN CONTROLLING DELAYED IMPLANTATION IN THE SPOTTED SKUNK
}

\author{
R. A. MEAD \\ Department of Biological Sciences, University of Idaho, \\ Moscow, Idaho 83843, U.S.A.
}

(Received 6th December 1971, accepted 28th February 1972)

Western forms of the spotted skunk breed in late September, at which time daylength is decreasing. Early cleavage and tubal transport are normal but implantation is delayed for approximately 220 days and further embryonic development is greatly retarded (Mead, 1968). Corpora lutea involute soon after their formation and progesterone secretion is minimal during embryonic diapause (Mead \& Eik-Nes, 1969a). The vulva enlarges in late April, at which time daylength is increasing, progesterone levels increase and embryonic development proceeds rapidly. Nidation is initiated a few days after luteal recrudescence and parturition occurs 29 to 31 days after implantation. These findings suggest that delayed implantation may result from insufficient gonadotrophin secretion during the preimplantation period.

The duration of the preimplantation period of the spotted skunk can be significantly shortened by increasing daylength (169 versus 218 days) or prolonged by blinding (265 versus 218 days) (Mead, 1971). Pineal synthesis of melatonin in mammals is likewise enhanced by darkness and inhibited by light (Wurtman, Axelrod \& Kelly, 1968). The latter compound has been demonstrated to have antigonadotrophic properties in that it can lower plasma levels of $\mathrm{LH}$ in rats (Fraschini, Mess \& Martini, 1968) and sheep (Roche, Foster, Karsch \& Dziuk, 1970) and has been reported to produce testicular regression in short-tailed weasels (Rust \& Meyer, 1969). It seemed possible, therefore, that the pineal gland of the spotted skunk might be producing an antigonadotrophin during periods of short daylength which was indirectly inhibiting ovarian function and thereby preventing implantation. The following experiment was designed to test this hypothesis by pinealectomizing pregnant spotted skunks obtained early in the prolonged (200- to 220day) preimplantation period.

Eleven, wild, pregnant, female spotted skunks (Spilogale putorius latifrons) were obtained from a trapper in Oregon and assigned to one of three treatment groups (Table 1). The temperature within the animal room was allowed to undergo natural fluctuations within a range of 10 to $25^{\circ} \mathrm{C}$ and illumination was by daylight only. The care and feeding of the skunks has previously been described (Mead, 1968).

All surgical procedures were performed under sodium pentobarbital anaesthesia $(40 \mathrm{mg} / \mathrm{kg}$ ) administered intraperitoneally. Pinealectomy was accomplished by the procedure described by Herbert (1969), though electrocautery 
was not employed and the caudal end of the corpus callosum was always transected. Sham operations were conducted in the same manner except that the pineal was not removed and the corpus callosum was not transected in two females. Upon termination of the experiment, the brains of all pinealectomized skunks and those subjected to sham operation were fixed in AFA (alcohol, formaldehyde, acetic acid) and serially sectioned at $8 \mu \mathrm{m}$ to confirm the success of the surgical procedure.

Monthly blood samples were obtained from each animal by cardiac puncture during the morning until the time of nidation, and the plasma assayed for progesterone by the gas chromatography method of van der Molen \& Groen (1965).

\section{TABLE I}

THE DURATION OF THE PREIMPLANTATION PERIOD IN INTAGT SPOTTED SKUNKS AND THOSE SUBJEGTED TO SHAM OPERATION AND PINEALEGTOMY

\begin{tabular}{c|l|c|c|c}
\hline $\begin{array}{c}\text { Animal } \\
\text { no. }\end{array}$ & \multicolumn{1}{|c|}{ Treatment } & $\begin{array}{c}\text { Date of } \\
\text { procedure* }\end{array}$ & $\begin{array}{c}\text { Duration of } \\
\text { preimplantation } \dagger\end{array}$ & Mean + S.D. \\
\hline 1119 & Intact & 3 Jan. & 214 days & \\
1137 & Intact & $\begin{array}{r}4 \text { Dec. } \\
\text { 24 Dec. }\end{array}$ & 216 days & $216 \pm 12 \cdot 8$ days \\
1151 & Intact & 28 Feb. & 234 days & \\
1158 & Intact & 12 Jan. & 230 days & \\
1149 & Sham operation & 25 Feb. & 206 days & $219 \pm 12 \cdot 1$ days \\
1153 & Sham operation & 28 Jan. & 221 days & \\
1157 & Sham operation & 8 Jan. & 212 days & \\
1147 & Pinealectomy & 9 Jan. & 213 days & $221 \pm 10 \cdot 0$ days \\
1148 & Pinealectomy & 27 Jan. & 232 days & \\
1152 & Pinealectomy & 8 Feb. & 227 days & \\
1156 & Pinealectomy & & \\
& &
\end{tabular}

* Date animals were received and subjected to experimental conditions.

$\dagger$ Day 1 of pregnancy was arbitrarily assumed to be 1 st October. Termination of the preimplantation period (day of nidation) was determined by vulval swelling and verified by laparotomy 2 to 4 days later.

Pinealectomy was complete in all animals (Pl. 1, Figs. 1 and 2) and none of the skunks showed visible signs of physical impairment after recuperating from surgery. Pinealectomy was ineffective in shortening the duration of the preimplantation period (Table 1) and there was no indication that the operation adversely affected postimplantation physiology, as two or more females in each treatment group reared normal healthy litters. Luteal function was likewise unaffected by pinealectomy as there was no significant difference $(P>0.05)$ between any of the means of monthly peripheral plasma levels of progesterone (Text-fig. 1).

Histological changes in pituitaries of mink (Baevskii, 1964) and European badgers (Herlant \& Canivenc, 1960) collected during the pre- and postimplantation periods suggest that there is inadequate gonadotrophic stimulation to maintain 'normal' ovarian function during the period of delayed implantation. Numerous experiments conducted with rodents suggest that the mammalian pineal gland is the source of an antigonadotrophic factor(s) (Wurtman et al., 1968; Reiter \& Fraschini, 1969), and that many of the effects of light on mammalian reproductive cycles are mediated through the pineal gland. 
PI..'Y\%, I

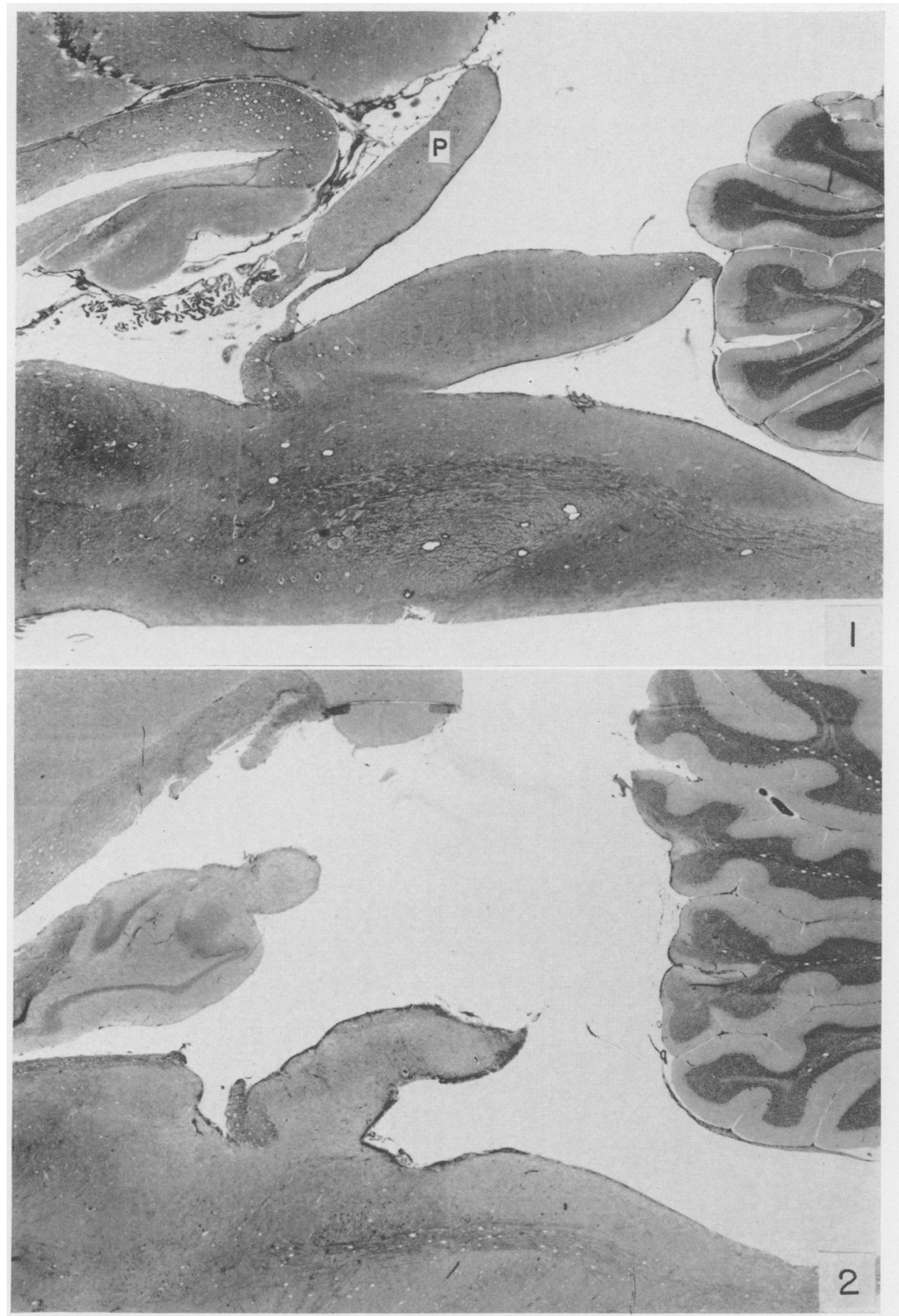

Lis. L Pineal ghand (p) of a spotted skunk (no. 1149 affer shan operation. $\times 14$.

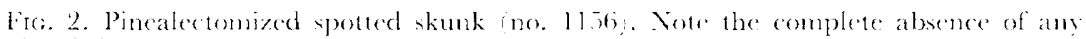
pincal tisute $\times$ t.

Farimef 1. 1+8, 
The gradual but progressive rise in peripheral plasma levels of progesterone and oestradiol-17 $\beta$ (Mead \& Eik-Nes, 1969a, b) during the prolonged preimplantation period in the spotted skunk suggest a gradual withdrawal of some inhibitory influence. Luteal involution and embryonic diapause in the spotted skunk occur when daylength is decreasing (September and early October) whereas luteal recrudescence and nidation occur at a time when daylength is increasing (April and May). Moreover, implantation and ovarian function in the spotted skunk can be accelerated or retarded by experimentally altering the photoperiod (Mead, 1971). Thus, it seemed logical that the pineal gland might play an important rôle in timing implantation.

The results of this experiment indicate that the observed effects of light are not mediated through the pineal gland; however, the eyes are obviously

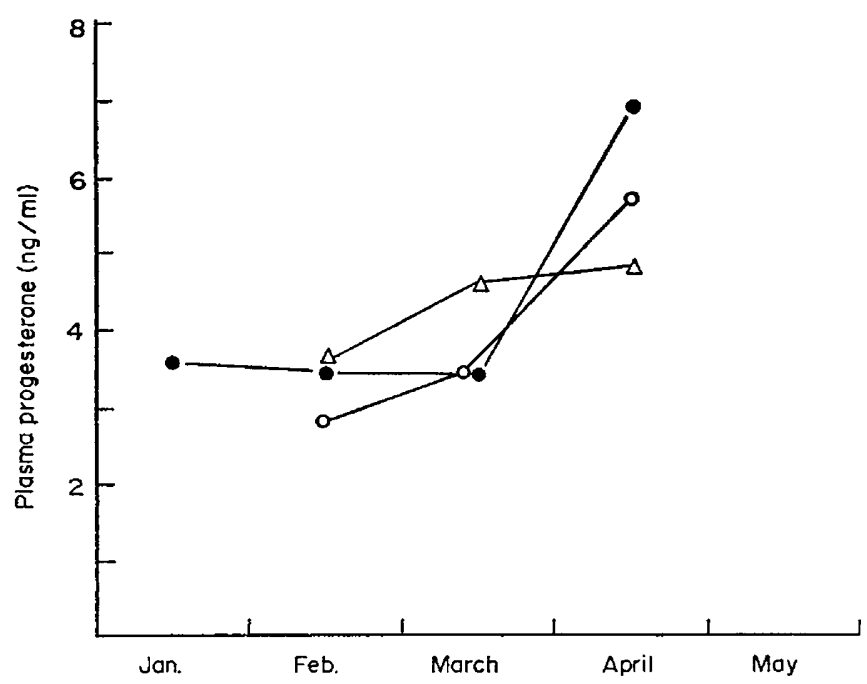

TeXT-Fig. 1. Effect of pinealectomy or sham operations on peripheral plasma levels of progesterone during the preimplantation period in Spilogale putorius latifrons. Each point represents the mean of three or four progesterone determinations. $\bullet$, Intact; $\Delta$, sham operation; $O$, pinealectomized.

involved as blinding inhibits implantation in the spotted skunk. The ewe is also a seasonal breeder and, like the skunk, usually breeds in September. The reproductive cycle of both species can be significantly altered by changes in photoperiod. Pinealectomy has been shown to have no effect on the seasonal breeding of ewes (Roche, Karsch, Foster, Takagi \& Dzuik, 1970), a finding which led these investigators to conclude that the pineal was not a predominant mediator of the effects of light on seasonal breeding in sheep. In ferrets, however, pinealectomy prevents the stimulating effect of artificial light (long days) on the premature onset of oestrus (Herbert, 1969), thus indicating that in this species the pineal gland may exert some control over the pars distalis.

Although this report is based upon a very limited amount of experimental evidence (only four pinealectomized animals), the data indicate that the pineal gland of the spotted skunk does not appear to be the source of an inhibitory 
substance which prevents implantation during periods of short daylength. They also suggest the existence of a more direct nervous pathway between the eyes and the hypothalamus.

This work was supported by a grant from the NIH (HD 04021). I would like to thank Dr Doyle Anderegg for his help in photographing the slides.

\section{REFERENCES}

BaEvskir, Y. B. (1964) Changes in the anterior lobe of the hypophysis, corpora lutea of pregnancy, and the thyroid of mink (Mustela vison) associated with implantation of embryos. Dokl. Akad. Nauk SSSR, 157, 1493.

Fraschini, F., Mess, B. \& Martini, L. (1968) Pineal gland, melatonin and the control of luteinizing hormone secretion. Endocrinology, 82, 919.

Herbert, J. (1969) The pineal gland and light-induced oestrus in ferrets. F. Endocr. 43, 625.

Herlant, M. \& Ganivenc, R. (1960) Les modifications hypophysaires chez la femelle du blaireau (Meles meles L.) au cours du cycle annuel. C. r. hebd. Séanc. Acad. Sci., Paris, 250, 606.

MEAd, R. A. (1968) Reproduction in western forms of the spotted skunk (genus Spilogale). F. Mammal. $49,373$.

Mead, R. A. (1971) Effects of light and blinding upon delayed implantation in the spotted skunk. Biol. Reprod. 5, 214.

MEAD, R. A. \& EIK-Nes, K. B. (1969a) Seasonal variation in plasma levels of progesterone in western forms of the spotted skunk. F. Reprod. Fert., Suppl. 6, 397.

Mzad, R. A. \& EiK-Nes, K. B. (1969b) Oestrogen levels in peripheral blood plasma of the spotted skunk. Biol. Reprod. 5, 215.

Reiter, R. J. \& Fraschini, F. (1969) Endocrine aspects of the mammalian pineal gland: A review. Neuroendocrinology, 5, 219.

Roche, J. F., Foster, D. L., Karsch, F. J. \& Dziuk, P. J. (1970) Effect of castration and infusion of melatonin on levels of luteinizing hormone in sera and pituitaries of ewes. Endocrinology, 87, 1205.

Roche, J. F., Karsch, F. J., Foster, D. L., Takagi, S. \& Dzruk, P. J. (1970) Effect of pinealectomy on estrus, ovulation and luteinizing hormone in ewes. Biol. Reprod. 2, 251.

Rust, C. C. \& Meyer, R. K. (1969) Hair color, molt, and testis size in male, short-tailed weasels treated with melatonin. Science, N.Y. 165, 921 .

VAN DER Molen, H. J. \& Groen, D. (1965) Determination of progesterone in human peripheral blood using gas-liquid chromatography with electron capture detection. F. clin. Endocr. 25, 1625.

Wurtman, R. J., Axelrod, J. \& Kelly, D. W. (1968) The pineal, pp. 58, 107. Academic Press, New York. 